\title{
Spigelian hernia in the right upper abdominal wall: a case report
}

\author{
Zhou Ye ${ }^{1 \dagger}$, Mo-Jin Wang ${ }^{2 \dagger}$, Li-Fen Bai ${ }^{2}$, Han-Xiang Zhuang ${ }^{2}$ and Wen Zhuang ${ }^{2^{*}}$ (D)
}

\begin{abstract}
Background: Spigelian hernia (SH) is rare and constitutes less than $2 \%$ of all hernias. It is reported that more than $90 \%$ of SHs lie in the "Spigelian belt", but SH in the upper abdominal wall is extremely uncommon. Here, we report a case of $\mathrm{SH}$ in the right upper quadrant of abdomen.

Case presentation: A 38-year-old female was admitted to hospital with complaints of abdominal pain and right upper quadrant mass for 10 days. Contrast-enhanced computed tomography (CECT) of abdomen revealed the dilated small intestine between the swelling ventral muscles in the right upper abdominal wall which suggested a ventral hernia. The surgeons considered it was a spontaneous hernia because there was no history of surgery or trauma in the upper abdomen. About two hours later, the patient underwent emergency surgery. According to laparotomy, a diagnosis of SH with ileum herniation in the right upper abdominal wall was confirmed. The necrotic ileum segment was resected. Meanwhile the abdominal wall defect was repaired by suturing the internal oblique and transverse muscles to the rectus sheath. The patient had a favorable outcome for 1 year without recurrence.
\end{abstract}

Conclusion: A mass and pain in the upper abdominal wall may suggest an atypical SH. SH occurring in the upper abdominal wall is a rare condition with possibility of dire outcome if not managed early.

Keywords: Spigelian hernia, Spontaneous, Strangulation, Surgery

\section{Background}

Spigelian hernia $(\mathrm{SH})$ is named after Adriaan van Spieghel, who depicted the semilunar line in 1645 [1]. The semilunar line is defined as the transition of the transversus abdominis muscle to its aponeurotic tendon [2]. Spigelian fascia is located between the semilunar line and the lateral edge of the rectus abdominis muscle. $\mathrm{SH}$ is a spontaneous abdominal hernia caused by a defect in the Spigelian fascia [3]. The hernia is rare and constitutes less than $2 \%$ of all hernias [4]. SH occurs anywhere on the Spigelian fascia, but it is reported that more than $90 \%$ of these hernias are located in the "Spigelian belt", which is a transverse 6-cm-wide zone in the lower abdominal wall (Fig. 1) [5]. However, SH occurring in the upper abdominal wall is extremely rare. We present a case of $\mathrm{SH}$ in the right upper quadrant.

\footnotetext{
* Correspondence: zhuangwen1966@163.com

${ }^{\dagger}$ Zhou Ye and Mo-Jin Wang contributed equally to this work.

${ }^{2}$ Department of Gastrointestinal Surgery, West China Hospital, Sichuan University, 37 Guo Xue Xiang, Chengdu 610041, Sichuan Province, China Full list of author information is available at the end of the article
}

\section{Case presentation}

A 38-year-old female patient presented with abdominal pain and right upper quadrant mass for 10 days. She had a history of pregnancy and caesarean section in the lower abdominal region 10 years before, but there was no history of trauma and upper abdominal surgery. Clinical examination showed a huge mass about $15 \times 10 \mathrm{~cm}$ over right upper abdomen. There was moderate tenderness in the area of the mass, and the abdominal skin was intact and smooth except the lower abdominal surgical scar. Abdominal wall ultrasonography showed mixed echo-mass under the muscle layer of right upper abdominal wall. Contrast-enhanced computed tomography (CECT) of abdomen was performed. The images revealed the dilated small intestine between the swelling ventral muscles in the right upper abdominal wall which suggested a ventral hernia in the right upper abdominal wall (Fig. 2). There was no history of right upper abdominal surgery or trauma, therefore the surgeons considered it was a spontaneous hernia. The patient had much more severe abdominal pain and began to present hematochezia during her hospitalization. Two hours later, she

(c) The Author(s). 2018 Open Access This article is distributed under the terms of the Creative Commons Attribution 4.0 International License (http://creativecommons.org/licenses/by/4.0/), which permits unrestricted use, distribution, and 


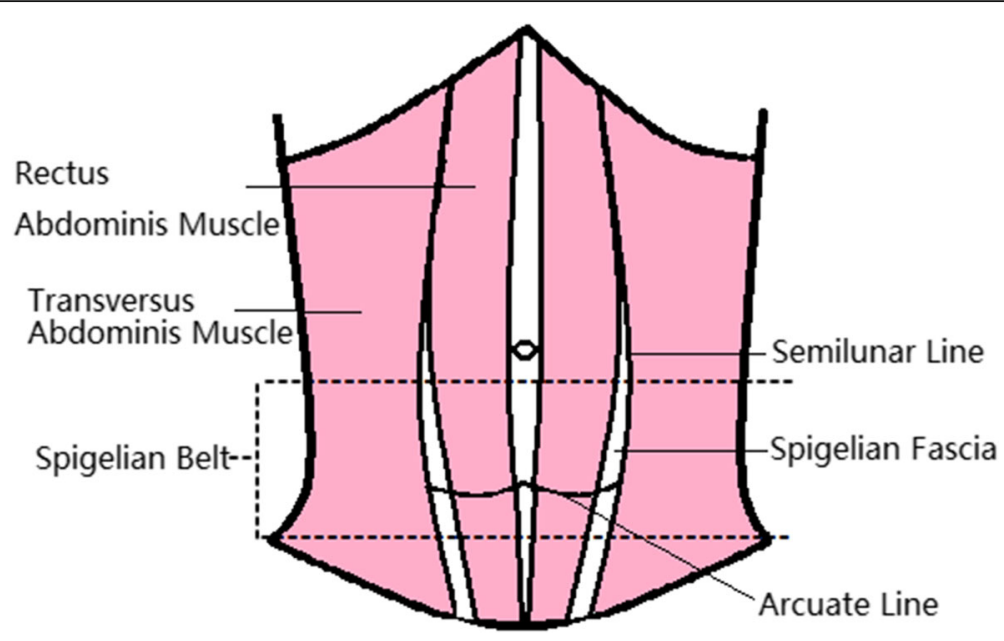

Fig. 1 The location of Spigelian fascia and "Spigelian belt"(The image in Fig. 1 was drawn by Zhou Ye)

underwent emergency surgery. The intraoperative finding was an atypical ventral hernia, and the ileum loop was incarcerated with necrosis. The hernia sac was located between the semilunar line and the edge of the rectus abdominis muscles in the right upper abdominal wall (Fig. 3), which confirmed it was a Spigelian hernia. The defect size was $2.0 \times 1.5 \mathrm{~cm}$. The necrotic ileum segment was resected and end-to-end anastomosis was performed. Considering the small defect and the necrotic ileum, a simple herniorrhaphy was made by suturing the internal oblique and transverse muscles to the rectus sheath. The postoperative course was uneventful, the patient recovered well and was discharged after 1 week of hospitalization. The patient had a favorable outcome for 1 year without recurrence.

\section{Discussion}

Spigelian hernia $(\mathrm{SH})$, also known as spontaneous lateral ventral hernia, usually occurs when abdominal pressure

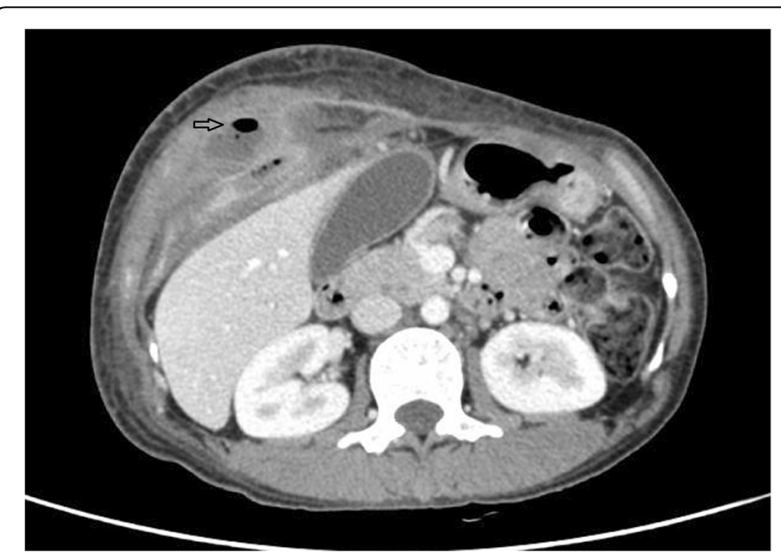

Fig. 2 CECT investigation revealed the presence of air between ventral muscles in the right upper abdominal wall increases. SHs in most cases have explicit predisposed causes, such as chronic coughing, obesity, peritoneal dialysis [6-12]. The site of the hernia is a significant indicator to identify SH. The Spigelian fascia is wider beneath the umbilical region, so it is weaker than that in the upper abdomen. However, superior to umbilical region, the transverses abdominis muscle and internal oblique muscle often extend into the posterior rectus sheath which makes the Spigelian fascia stronger [3]. Anatomically, $\mathrm{SH}$ occurring in the upper abdomen is uncommon. Furthermore, in the upper abdominal wall, the Spigelian fascia is posterior to the rectus muscle, making it difficult even for the experienced surgeon to locate a fascial defect during the physical examination.

Ultrasound is recommended as first line imaging investigation, and CT scanning should be added in challenging cases [13-15]. Other studies show that the CT

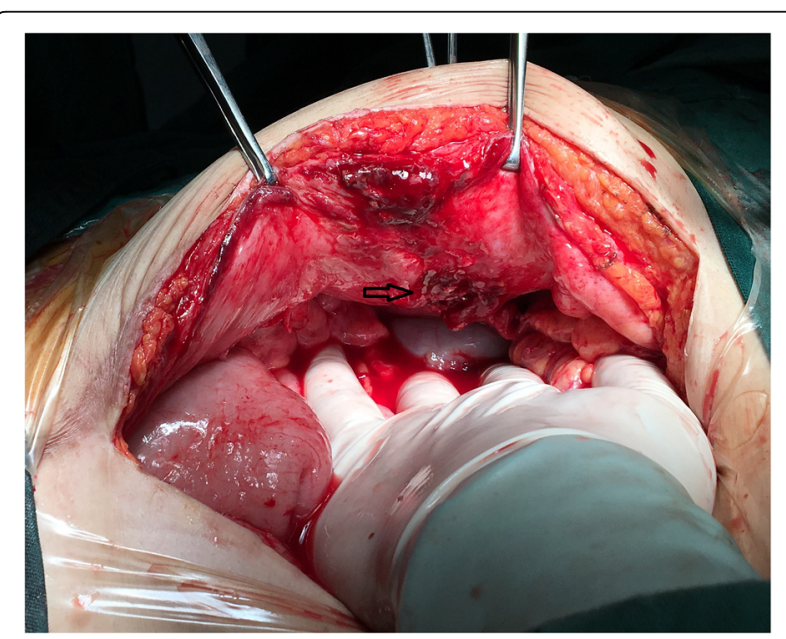

Fig. 3 The hernia sac (arrow) was located between the semilunar line and the edge of the rectus abdominis muscles 
scanning is better than ultrasound, because ultrasound is dependent by the operator [11, 16]. Still, it is reported that only $50 \%$ of cases are correctly diagnosed preoperatively [17].

$\mathrm{SH}$ is dangerous and the risk of incarceration is higher than other hernias because the defect can be small. It is reported that the risk of incarceration is up to $21 \%$, and thus patients should be offered prompt surgical repair [18]. Surgical procedures are generally classified as open and laparoscopic procedures. The laparoscopic approach should be applied in uncomplicated cases $[19,20]$. If the defect is extensive (usually more than $5 \mathrm{~cm}$ ) and the abdominal wall is obviously destructive, open surgery should be performed [3]. Repairing the defect of $\mathrm{SH}$ contains fascial closure or fascial suturing reinforced with synthetic mesh in the cases of large defects [21, 22]. Small hernia defects could be repaired by laparoscopic herniorrhaphy alone [23].

In conclusion, a mass and pain in the upper abdominal wall may suggest an atypical $\mathrm{SH}$. In addition, the risk of strangulation of $\mathrm{SH}$ is higher than other hernias. $\mathrm{SH}$ occurring in the upper abdominal wall is a rare condition with possibility of dire outcome if not managed early.

\section{Additional files}

Additional file 1: $C T$ 1. CECT investigation revealed the ventral hernia (transverse section 1). (TIF $73 \mathrm{~kb}$ )

Additional file 2: $C T$ 2. CECT investigation revealed the ventral hernia (transverse section 2). (TIF $73 \mathrm{~kb}$ )

\section{Abbreviations}

CECT: Contrast-enhanced computed tomography; CT: Computed tomography; SH: Spigelian hernia

\section{Acknowledgements}

The author (s) declare that they have no acknowledgements.

Funding

The author (s) declare that they have no funding.

\section{Availability of data and materials}

All attainable data are within in the paper and the Additional files 1 and 2. All data are fully available without restriction.

\section{Authors' contributions}

ZY and MJW designed the study and drafted the manuscript. MJW, WZ, HXZ and LFB contributed case information and participated in data analysis. All authors approved the final version of the manuscript.

\section{Ethics approval and consent to participate}

Ethical approval was given by the medical ethics committee of West China Hospital of Sichuan University.

\section{Consent for publication}

Written informed consent was obtained from the patient for publication of this case report and any accompanying images. A copy of the written consent is available for review by the editor of this journal.

\section{Publisher's Note}

Springer Nature remains neutral with regard to jurisdictional claims in published maps and institutional affiliations.

\section{Author details}

'Department of Digestive Diseases, The Third Affiliated Hospital of Chongqing Medical University (Gener Hospital), Chongqing, China.

${ }^{2}$ Department of Gastrointestinal Surgery, West China Hospital, Sichuan University, 37 Guo Xue Xiang, Chengdu 610041, Sichuan Province, China.

Received: 27 December 2017 Accepted: 16 November 2018 Published online: 27 November 2018

\section{References}

1. Spangen L. Spigelian hernia. World J Surg. 1989;13(5):573-80.

2. Sachs M, Linhart W, Bojunga J. The so-called Spigelian hernia--a rare lateral hernia of the abdominal wall. Zentralblatt fur Chirurgie. 1998;123(3):267-71.

3. Webber V, Low C, Skipworth RJE, Kumar S, de Beaux AC, Tulloh B. Contemporary thoughts on the management of Spigelian hernia. Hernia. 2017;21(3):355-61.

4. Polistina FA, Garbo G, Trevisan P, Frego M. Twelve years of experience treating Spigelian hernia. Surgery. 2015;157(3):547-50.

5. Skandalakis PN, Zoras O, Skandalakis JE, Mirilas P. Spigelian hernia: surgical anatomy, embryology, and technique of repair. Am Surg. 2006;72(1):42-8.

6. Jazayeri SB, Tsui JF, Samadi DB. Abdominal mass after robotic assisted laparoscopic prostatectomy: Spigelian type trocar hernia. Curr Urol. 2017; 10(3): $163-5$

7. Tsalis $\mathrm{K}$, Zacharakis E, Lambrou I, Betsis D. Incarcerated small bowel in a spigelian hernia. Hernia. 2004;8(4):384-6.

8. Cano-Maldonado AJ, Alcazar-Montero JA, Gonzalez-Fernandez JM, AdrioDiaz G. Outside-the-ribcage thoracic migration of a spigelian hernia. Hernia. 2009;13(1):89-92.

9. Dixon E, Heine JA. Incarcerated Meckel's diverticulum in a Spigelian hernia. Am J Surg. 2000;180(2):126.

10. Ramones MT, Beech D. Incarcerated Spigelian hernia: a rare cause of mechanical small-bowel obstruction. J Natl Med Assoc. 2010;102(8):731-3.

11. Rogers FB, Camp PC. A strangulated Spigelian hernia mimicking diverticulitis. Hernia. 2001;5(1):51-2.

12. Gough VM, Vella M. Timely computed tomography scan diagnoses spigelian hernia: a case study. Ann R Coll Surg Engl. 2009;91(8):W9-10.

13. Kassir R, Tarantino E, Lacheze R, Brek A, Di Bartolomeo A, Tiffet O. Management of Spigelian hernia caused by necrobiotic fibroma of the uterus in a pregnant woman. Int J Surg Case Rep. 2013;4(12):1176-8.

14. Spinelli C, Strambi S, Pucci V, Liserre J, Spinelli G, Palombo C. Spigelian hernia in a 14-year-old girl: a case report and review of the literature. European J Pediatr Surg Rep. 2014;2(1):58-62.

15. Capaccio E, Di Vito L, Derchi LE. Epiploic appendage torsed within a spigelian hernia: US and CT findings. J Clin Ultrasound. 2012;40(5):310-3.

16. Zacharakis E, Papadopoulos V, Ganidou M, Zacharakis E. Incarcerated Spigelian hernia: a case report. Med Sci Monit. 2006;12(7):Cs64-6.

17. Mittal T, Kumar V, Khullar R, Sharma A, Soni V, Baijal M, Chowbey PK. Diagnosis and management of Spigelian hernia: a review of literature and our experience. J Minim Access Surg. 2008:4(4):95-8.

18. Sharma H, Rich L, Kelly MD. Spigelian hernia presenting as an appendicular mass. South Med J. 2007;100(10):1037-8.

19. Moreno-Egea A, Flores B, Girela E, Martin JG, Aguayo JL, Canteras M. Spigelian hernia: bibliographical study and presentation of a series of 28 patients. Hernia. 2002;6(4):167-70.

20. Baucom C, Nguyen QD, Hidalgo M, Slakey D. Minimally invasive spigelian hernia repair. JSLS. 2009;13(2):263-8.

21. Onal A, Sokmen S, Atila K. Spigelian hernia associated with strangulation of the small bowel and appendix. Hernia. 2003;7(3):156-7.

22. Losanoff JE, Jones JW, Richman BW. Recurrent Spigelian hernia: a rare cause of colonic obstruction. Hernia. 2001:5(2):101-4.

23. Bittner JG, Edwards MA, Shah MB, MacFadyen BV Jr, Mellinger JD. Mesh-free laparoscopic spigelian hernia repair. Am Surg. 2008;74(8):713-20 discussion 720.

\section{Competing interests}

The authors declare that they have no competing interests. 